\title{
Uma romancista francesa e um diretor português: relação entre literatura e cinema
}

Viviane Cunha

Universidade Federal de Minas Gerais

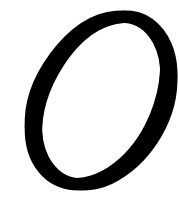

diálogo entre dois autores, Madame de La Fayette e Manoel de Oliveira, em registros distintos (livro e filme), procedentes de épocas tão distantes, se estabelece através de um dos mais antigos meios de comunicação: a carta. Ela, escritora do século XVII, época em que a mulher raramente assinava seus trabalhos, e precisava se esconder sob um pseudônimo, criou um romance que é considerado um clássico da literatura francesa. Ele, diretor de cinema, consagrado em Cannes, "inteligente" leitor da obra de Madame de La Fayette, compôs uma obra, que poderá se tornar um clássico do cinema contemporâneo. Ao tempo para confirmar isso. Considerarei, neste estudo, a cronologia, para estabelecer uma relação entre o romance e o filme, iniciando, pois, pela análise de A Princesa de Clèves, de Madame de La Fayette.

\section{O romance}

O romance $A$ Princesa de Clèves foi publicado em 1678, anonimamente, junto ao editor Claude Barbin, em Paris, o qual foi o responsável pelas edições dos grandes escritores antigos, bem como os do século de Luis XIV. A ação do romance se passa, no século antecedente, o século XVI, e tem como cenário 
as cortes, entremeando o factual e o ficcional. Na boa sociedade do século XVII, ser autor não era uma qualidade da qual se podia vangloriar a aristocracia; é em razão disso, talvez, que certos críticos literários consideram $A$ Princesa de Clèves como uma obra coletiva. Na opinião de alguns deles, Madame de La Fayette teria se aconselhado com o seu amigo La Rochefoucauld, e com outros autores do nível de Segrais e de Huet (ambos da Academia Francesa), bem como com Madame de Sévigné, epistolária de renome, simpatizante do jansenismo. Essa última conseguiu a reputação de escritora através de suas cartas, tendo sido uma grande amiga de Madame de La Fayette. Se, por um lado é difícil reconhecer a parte de cada um dos autores, no romance, os historiadores da literatura, porém, têm quase certeza de que Madame de La Fayette foi a arquiteta dessa obra, foi ela quem insuflou aí a sua energia, e assegurou a coerência do romance, escrito entre 1672-1677. O nome da autora só aparecerá na capa do romance em 1780, ou seja, mais de cem anos após a sua primeira edição.

Marie-Madeleine Pioche de La Vergne (1634-1693) nasceu numa família de pequena nobreza rica, casou-se com o conde de La Fayette, também escritor, o qual, eclipsado por sua mulher, desapareceu dos meios literários. Depois de viver algum tempo na Auvérnia, Madame de La Fayette passou a viver em Paris. Sua educação literária começou com o escritor Gilles Ménage, que lhe ensinou italiano e latim, e a introduziu no salão literário de Madeleine de Scudéry; mais tarde ela abriria seu próprio salão. A propósito, é bom lembrar que os salões literários, como ambientes nos quais se divulgava a literatura, e as cartas como gênero literário em voga, foram apanágios da literatura francesa, do século XVII.

Uma vez estabelecida definitivamente em Paris, Madame de La Fayette manteve contato com o Grande Arnauld - o autor da gramática de Port Royal - e os principais autores franceses da época. Em 1662, foi publicado anonimamente $A$ princesa de 
Montpensier, seu primeiro romance. De 1655 a 1680, manteve ligações estreitas com La Rochefoucauld, que a apresentou a Racine e a Boileau, os grandes espíritos literários da época. Em 1669 , foi publicado o primeiro volume de Zaïde, um romance hispano-mourisco, com a assinatura de Segrais. O segundo volume dessa obra apareceu em 1671, tendo sido objeto de muitas reedições e traduções, graças ao prefácio de Huet, um tratado da origem dos romances. Todavia, é $A$ Princesa de Clèves (1678) o romance mais célebre de Madame de La Fayette, cuja edição princeps apareceu anônima. Essa obra obteve um imenso sucesso na época, tendo sido considerada como o primeiro romance francês autêntico, um protótipo do romance psicológico. A morte de La Rochefoucauld, em 1680, e depois a de seu marido, em 1683, levou Madame de La Fayette a ter uma vida social menos ativa, nos seus últimos anos. Ela se afastou da vida mundana, com o intuito de se preparar para a morte, perspectiva escatológica muito comum, na época. Três de suas obras foram editadas postumamente: $A$ Condessa de Tende (1718), História de Henriqueta da Inglaterra (1720) e Memórias da Corte da França (1731).

O conjunto da obra de Madame de La Fayette teve uma excelente repercussão e causou uma profunda impressão nos seus contemporâneos e nos autores dos séculos posteriores. Para Voltaire,

A princesa de Clèves e Zaïde foram os primeiros romances, onde se pôde ver os bons costumes das pessoas honestas, e aventuras naturais, descritas com graça. Antes dela, usavase um estilo pomposo, afetado, de coisas pouco verossímeis. ${ }^{1}$

Muitos escritores evocaram, nas suas obras, A Princesa de Clèves: Cocteau, Stendhal, Sainte-Beuve (jansenista), entre outros, o que evidencia o seu caráter de romance paradigmático.

${ }^{1}$ VOLTAIRE, [s.d.], p. 127. 
Estruturalmente, o romance $A$ Princesa de Clèves se compõe de quatro partes. A ação se desenrola em 1558, na corte do rei Henrique II, durante os últimos anos de seu reinado, quando príncipes e princesas se rivalizam em elegância e galanteria, em volta do rei. A primeira parte do romance apresenta a Senhorita de Chartres, personagem principal, jovem órfã de 16 anos, educada pela mãe, segundo regras rigorosas de moral, que aparece, inicialmente, no Palácio do Louvre ${ }^{2}$, a residência real naquela época. O príncipe de Clèves, homem de grande retidão moral, apaixona-se pela jovem, quando a vê junto a um joalheiro italiano, localizado na Place Vendôme, em Paris. Completamente cego por sua beleza a pede em casamento; inexperiente no amor, ela o aceita como esposo, mesmo não estando apaixonada. Depois de casada, e já como Princesa de Clèves, vem a conhecer, na corte, o duque de Nemours. Nasce entre eles um amor imediato. Madame de Chartres, mãe da Princesa, descobre essa paixão, e mantém-se vigilante, não permitindo que sua filha caia nos braços do duque. Porém, a mãe adoece gravemente, e antes de morrer convence sua filha a lutar contra o que considera um "amor culpado". Ao perder a proteção da mãe, a Princesa retira-se para o campo, a fim de evitar Nemours, e seu marido permanece em Paris, no intuito de consolar o amigo Sancerre, que no dia da morte de sua amada - a Senhora de Tournon - vem a saber que ela amava Estouville, a quem escrevera algumas cartas, as quais chegaram-lhe, por acaso, às mãos.

É de se notar, nessa primeira parte do romance, dois casos de amor não correspondido: o de Clèves e o de Sancerre, temática recorrente no gênero romance. A propósito, os amores

\footnotetext{
${ }^{2}$ Originalmente, um castelo forte; no reinado de Carlos V, esse o transforma em residência real, até que Luis XIV, em 1678, escolheu Versalhes como residência real. No século XVIII, o Palais du Louvre transformou-se em museu.
} 
infelizes são uma constante nas obras de Madame de La Fayette; não é pois sem razão, que Camus afirmou que para a autora o amor é algo perigoso. (cf. Camus, 1964).

Na segunda parte do romance, a carta terá um papel essencial na trama. A Princesa de Clèves, que vive na sua casa de Coulommiers (a leste de Paris) retorna à capital francesa, e toma conhecimento do drama de Sancerre; preocupando-se, quando percebe a comoção de seu marido em relação ao amigo. Não conseguindo superar os seus sentimentos, a Princesa está bem decidida a vencer os seus atos, fugindo daquele a quem ama. No entanto, Nemours renuncia às expectativas de uma coroa, por amor a ela: ele rouba seu retrato que estava exposto na Corte, e ela que havia presenciado tal cena, se cala. Nemours interpreta a falta de reação da Princesa, da maneira que lhe convém, sentindo-se correspondido. Aqui, se apresenta um dos vários equívocos do romance: a Princesa se cala apenas por medo de vir à tona o amor de ambos, medo do escândalo, e das consequências que adviriam. Certo dia, durante um torneio, Nemours se fere, e o olhar que lhe dirige a Princesa é uma prova de seu amor. Porém, quando encontra uma carta perdida - de mulher - nasce a suspeita de que ele tenha uma ligação amorosa, e sente ciúmes.

Esse é o pretexto para o início da terceira parte do romance. $\mathrm{O}$ Vidame $^{3}$ de Chartres, tio da Princesa e amigo íntimo de

${ }^{3}$ Vidame, composto de vice e do latim dominus, 'senhor', é um titulo de nobreza francês bastante raro. O vidame é, na sua origem, aquele que conduz o exército de um bispo, e exerce em nome dele, um certo número de direitos feudais. Na época moderna, o título está integrado à hierarquia aristocrática, como equivalente de visconde. $\mathrm{O}$ título de Vidame de Chartres estava ligado à terra do CasteloArnault (ou Castelo-Vidame). 
Nemours, fica contrariado com a carta, que pertencia a ele, e se sente pior, quando pensa na possibilidade de sua circulação entre todas as mãos da Corte, o que desonraria uma mulher respeitável, e despertaria a cólera da Rainha, que lhe havia feito seu confidente. Nemours, a pedido do Vidame de Chartres, assume ser o destinatário da carta, e reclama-a com a filha da rainha, que a tem, então, em suas mãos. Tendo consigo um bilhete, que lhe permitirá justificar-se junto à Princesa de Clèves, o equívoco será desfeito. Em seguida, na presença de Clèves, Nemours e da Princesa, atendendo a um pedido real, reescrevem de memória uma cópia da carta que semeou o problema, tentando imitar o estilo e a letra da mesma. Como a Princesa de Clèves a havia relido várias vezes, ela conhecia bem seu conteúdo. Com a proximidade de Nemours, percebe a paixão que sente por ele e se retrai. Decidindo partir novamente para o campo, a Princesa resolve, antes, confessar ao marido, que está enamorada de outro homem, e que para continuar digna dele, ela precisa deixar a Corte. Nemours, escondido, ouve a confissão. Tranquilo, num primeiro momento pela franqueza e coragem da esposa, depois o marido começa a sentir um forte ciúme e a pressiona com perguntas, às quais ela não responde, não lhe revelando, da mesma forma, o nome do seu rival. Ao ficar só, a Princesa se assusta com sua confissão dando-se conta porém, de que dera uma prova de fidelidade ao seu marido. Nemours, por sua vez, entende que essa confissão lhe tira toda a esperança; todavia, experimenta um certo orgulho de amar e de ser amado por uma mulher tão nobre. Mas, comete a imprudência de contar, ao Vidame de Chartres, em termos vagos, a história que ele acaba de viver, e o amigo acaba por adivinhar que essa é a sua própria história. Clèves vem a saber que é Nemours o amado de sua esposa. Em meio a todo esse transtorno, o rei 
Henrique $\mathrm{II}^{4}$ morre durante um torneio. Um oráculo lhe havia dito que ele morreria lutando. Curiosamente, esse rei era admirador do Amadis de Gaula, dado factual que não está no romance de Madame de La Fayette.

A morte do rei dá inicio à quarta parte do romance. Enquanto a Corte vai a Reims para a coroação do novo rei Francisco II - a Princesa se retira novamente para o campo, buscando, na solidão, a impossível tranquilidade. Nemours a segue, sob a vigilância de um amigo de confiança de Clèves. À noite, Nemours observa a Princesa, a contemplar, com ar sonhador, um quadro, no qual ele está representado. A presença de Nemours, próximo à princesa, foi relatada a Clèves, pelo seu amigo. Sem deixar seu interlocutor dar-lhe maiores detalhes, Clèves, persuadido de que fora traído, acaba morrendo de melancolia, algum tempo depois, sem ter dito adeus "à virtuosa infiel". A dor tira toda a razão da Princesa, que experimenta por si mesma e por Nemours um verdadeiro pânico; ela se recusa a vê-lo, temendo que seu defunto marido possa vê-la se casar com ele. Finalmente, o Vidame de Chartres consegue organizar uma entrevista secreta entre os dois enamorados. Ela olha Nemours com doçura, aconselha-o a procurar, em outro lugar, um destino mais feliz, e sai, sem que ele possa retê-la. A Princesa tentará acalmar a sua dor exilando-se nos Pirineus, onde possui

${ }^{4}$ Filho de Francisco I, Henrique II herda, em 1547, o mais poderoso e
rico reino europeu. Apreciador dos torneios e dos exercícios violentos,
esse rei não é muito apreciado pelos historiadores. Casado com
Catarina de Médicis, e amante de Diana de Poitiers, do casamento
com Catarina nasceram dez filhos. O mais velho é Francisco II, futuro
esposo de Maria Stuart, que o sucederá no trono. Maria Stuart aparece
nas festas da coroação de seu esposo, com as jóias tomadas de Diana
de Poitiers (dado factual, narrado no livro de Madame de La Fayette). 
propriedades, e morrerá alguns anos mais tarde, sucumbindo a uma apatia.

Como se pode constatar, a carta é o elemento principal de toda a trama do romance de Madame de La Fayette, é ela a mola propulsora de todos os equívocos; é o fio condutor do romance, que acabou por sugerir o título a Manoel de Oliveira, no seu filme.

Admite-se, geralmente, que a carta é um dos gêneros literários, para não dizer o gênero literário [por excelência], no qual as mulheres encontraram um (primeiro) meio de se exprimir, de entrar na literatura, e através dela, de se liberar. ${ }^{5}$

Segundo Ruth Amossy (1998, p. 73),

a correspondência amorosa se situa na confluência de dois tipos de discursos, no qual, ela combina as regras e os artifícios (.... 'o discurso epistolar e o discurso amoroso', esse último fornecendo-lhe todo um aparato de modelos: declaração, sedução, solicitação, querela, recusa, ruptura, etc. ${ }^{6}$

A grande voga da carta literária procede, de certa maneira, do desejo vaidoso de aparecer, de ser apreciada, de merecer elogios pela qualidade do seu estilo, e do aprofundamento de suas reflexões. Tem-se o desejo de escrever sobre o que se faz e o que se diz nos meios aristocráticos. O século XVII é o grande século dos escritores epistolares. A carta não se dirige a um só destinatário, ela é lida e comentada, no círculo mundano ao qual pertence, como se pode constatar no romance de Madame de La Fayette. Institui-se, desde então, toda uma rede de intercâmbios e de comunicações, entre os salões de Paris (ou Versalhes, centro da Corte francesa) e o da Província. As

${ }^{5}$ DUCHÊNE, 1998, p. 27.

${ }^{6}$ AMOSSY, 1998, p. 73. 
questões e as respostas se encadeiam numa escrita cuidada. A carta não é simplesmente uma correspondência privada, mas se torna uma criação, destinada a um público. A sinceridade se perde, certamente, em favor de exercícios de um estilo artificial e carregado. Se, por um lado, as cartas de Madame de Sévigné guardam ainda um aspecto de conversações íntimas, grande parte das cartas que compõem as antologias do século XVII é endereçada mais aos leitores anônimos, às vezes póstumos, do que ao próprio destinatário. Trata-se mais de uma prática de estilo, exibição de um certo virtuosismo. O século XVII é o de uma nova arte de viver; a corte desenvolve essa nova arte com suas regras, seus códigos, que o "homem honesto", esse ideal de homem do mundo e homem de Corte, respeita. Essa arte de viver passa por um prazer pela comunicação, que acaba se tornando uma necessidade. A conversação se torna uma arte, e a correspondência mais ainda: falar e escrever bem para testemunhar de maneira engenhosa e espiritual a vida, essa é a razão pela qual se escreve, muito mais do que para falar de coisas íntimas ou familiares. Passa-se a ter um grande cuidado na redação de cartas, a dar-lhes um valor literário e artístico. Paris e Versalhes, a cidade e a Corte, centros intelectuais, políticos, artísticos fornecem a essas cartas o essencial de suas matérias.

\section{O filme}

O filme $A$ carta, do diretor português Manoel de Oliveira, é a transposição para o século XX, da obra de Madame de La Fayette - A Princesa de Clèves - escrita no século XVII, retratando aspectos factuais do século XVI, conforme relatado acima. O filme se inicia com a apresentação de um concerto de piano, pela artista portuguesa Maria João Pires executando Schubert, na sala de concertos da Fundação Calouste Gulbenkian, em Paris, o que remete ao mundo ao qual Catherine de Chartres 
(personagem principal) estava acostumada a frequentar. Numa cena subsequente aparece um show de música pop, onde Pedro Abrunhosa (que interpreta a si mesmo) se apresenta, e a jovem fica fascinada pela sua música e pelo cantor.

A estrutura narrativa do filme caracteriza-se pela simplicidade, mas a organização interna dos planos é construída com precisão, minuciosamente. "Essa tragédia sentimental [realizada pelo cineasta português] toma a forma de uma coreografia de palavras, onde as personagens seriam dançarinosenunciadores" (matéria de divulgação do filme). Dessa forma, no filme de Manoel de Oliveira, o príncipe Nemours torna-se Pedro Abrunhosa, um cantor pop de grande sucesso. Guise - no romance de Madame de La Fayette, é um amigo de Clèves, que ao perceber a paixão do amigo pela jovem Princesa desiste do sentimento que nutria por ela - no filme, se transformará num jovem que sofre um atropelamento, no Boulevard Port-Royal, saindo logo de cena. Catherine de Clèves tem, como confidente, uma religiosa jansenista, a quem confia os tormentos de seu coração, depois de haver confessado, ao marido, a paixão que a consumia. Essa infidelidade, ainda que seja apenas no nível espiritual, é a responsável pela morte do marido. Na realidade, a personagem principal do romance ou do filme se serve de sua faculdade de introspecção como de uma arma para lutar contra o apelo da paixão. Evocando um amor recusado, mais do que um amor impossível, o romance se inscreve na linha de um pessimismo moral, perceptível em Racine e em La Rochefoucauld, cuja nuance pode ser atribuída à influência da corrente jansenista, e que ficará mais transparente no filme de Manoel de Oliveira. A partir do texto de Madame de La Fayette, Oliveira anda rápido, substituindo passagens inteiras, utilizando mesmo uma língua que não é atual, nem tampouco a do século XVII, trata-se porém de uma linguagem bem cuidada.

Catherine de Chartres é apresentada a um médico renomado, Jacques de Clèves, por uma amiga da família, a Senhora da 
Silva. O médico apaixona-se pela jovem, quando a vê em companhia de sua mãe, numa joalheria famosa da Place Vendôme, em Paris, no momento em que experimentava um colar. Ele a pede em casamento e ela o aceita como marido, mesmo não estando apaixonada. Mais tarde, a jovem esposa conhece um cantor de rock famoso, Pedro Abrunhosa, por quem se apaixona. Percebendo o amor que está desabrochando na filha a Senhora de Chartres, que adoecera subitamente, lhe aconselha a ser prudente. Não tendo mais os conselhos da mãe, que morre no início do filme, a jovem passa a visitar regularmente uma colega de escola, que se tornara religiosa, e vive num convento, em Paris. Cada vez mais pressionada pelo que sente por Pedro Abrunhosa, Catherine decide revelar ao marido os seus verdadeiros sentimentos, na tentativa de que ele a ajude nesse dilema. O marido, ao confirmar o que já suspeitava antes, morre pouco tempo depois de conhecer a verdade. Viúva, Catherine não se casará com o cantor, que faz muito sucesso junto ao público feminino. Sem dizer nada a ninguém, ela desaparece do cenário. Certo dia, sua amiga religiosa, a quem ela visitava frequentemente, recebe uma carta proveniente da África. Catherine havia partido para lá, com um grupo de missionários, onde fora socorrer as populações maltratadas pela guerra civil, pela doença e pela fome. Esse é o único momento, no filme, em que há referência à "carta". O que em Madame de La Fayette constitui toda a trama do romance, sendo a fonte de todos os equívocos, em Manoel de Oliveira, a "carta" é um símbolo que remete a Port Royal, ao jansenismo - o convento e o retrato da religiosa na parede são indícios disso -, fechando o filme. O que está implícito no romance, no filme se torna explícito, pois, na realidade, a personagem principal do filme, assim como do romance, incorpora um dos conceitos básicos do jansenismo: o rigor moral. Segundo a crítica cinematográfica, A Carta é uma montagem de trechos da obra de Madame de La Fayette, mas 
é preciso admitir-se que a caracterização das personagens principais, guardadas as devidas distâncias temporais, permanece literalmente a mesma do romance.

Numa das partes centrais do filme, aparece um trio (Catherine, Jacques de Clèves e Pedro Abrunhosa), no Jardim de Luxemburgo, onde a jovem esposa confessa a sua paixão por outro homem, e o cantor, escondido, ouve tudo. No romance de Madame de La Fayette, esse é o ponto culminante da narrativa, é o fio que reconduzirá toda a trama ao seu final. No filme, essa cena se passa como numa situação teatral. O mendigo, que aparece rapidamente no Jardim de Luxemburgo, não existe no romance. A cena do diálogo entre o casal se passa diante da estátua de um Fauno, que tem à mão uma carta, o que justificaria, junto com a carta final do filme, o seu título. Na mitologia romana, Fauno (em latim Faunus, 'o favorecedor' - de favere ou talvez 'o portador' - de fari - era uma das divindades mais populares e antigas, identificado com o grego Pan, devido à similitude de seus atributos).

Sobre o título do filme de Manoel de Oliveira, um crítico do Le Monde, Jean-Michel Frodon, faz o seguinte comentário:

desde sempre, em qualquer recanto do mundo, da ética à política, e da literatura ao cinema, a carta é a relação entre cada pessoa, por intermédio do espaço público. É a democracia e o espírito de resistência aos conformismos dos sentidos, e também, dos costumes, que formam o jogo desta história, aparentemente, grande burguesa e sentimental, daí, ao fim desse percurso encantado, a força concentrada da carta, enviada pela senhora de Clèves, inserida no filme por Manoel de Oliveira, lida pela religiosa. Em palavras simples ele diz a sua fúria contra o estado do mundo atual e a possibilidade de enfrentá-lo. ${ }^{7}$

\footnotetext{
${ }^{7}$ FRODON: 1999.
} 
O quadro da cena inicial do filme-Catherine, em companhia da mãe, experimentando um colar, sob o olhar fascinado de Jacques de Clèves - faz um contraponto com um verdadeiro quadro, o da religiosa do convento de Port-Royal, onde acontece um encontro, que transformará a vida da jovem. Mais do que uma história de renúncia, na linha de "amores frustrados", caros a Manoel de Oliveira, A Carta mostra esta oscilação sutil entre um rosto dividido pelo desejo de se dar a outro, e a vontade repentina de se afastar. Um rosto que hesita, antes de fazer uma escolha irreversível. Finalmente, o rosto desaparece por trás da "carta" e só se exprime por palavras. A jovem mulher se torna o quadro (contemplado pela religiosa, o qual é o símbolo de Port Royal), que se funde inteiramente na tela. A Senhora de Clèves deixou o nosso mundo, o da circulação do desejo, por outro invisível, distante, misterioso, e que o diretor julgou, talvez, infilmável. (cf. FRODON: 1999.)

Essa palpitação da carne que se oferece e se retira, sublimação plástica de um movimento erótico, culmina na cena central, na qual, a Senhora de Clèves conhece Pedro Abrunhosa, o homem que a deseja, persegue e pressiona a amá-lo, instalando-se em frente a ela. A jovem aparece, no quadro da janela, se dá a ele, sem reserva, para que ele possa desfrutar da sua presença, quando, uma corrente de ar faz com que a cortina tampe o seu rosto (antecipação da tomada do véu), o esconde, à medida que se oferece, e o torna mais belo. À crueza obscena do dar a outro, sem artifício, o diretor prefere a beleza fantasmada de um rosto, por trás do véu, expressão da força soberana de um plano de cinema. Quando ela se encontra diante do quadro, que representa a religiosa - figura ligada à doutrina jansenista, cujo ponto central é a questão da graça eficaz, a predestinação a se realizar o bem - seu rosto parece fascinado. ${ }^{8}$

${ }^{8}$ FRODON: 1999. 
É possível, que Manoel de Oliveira tenha transportado o fascínio que a Princesa de Clèves sente ao contemplar um quadro, no qual figura Nemours, porém, com um olhar amoroso, e no filme, isso se transforme em sublimação: o amor a todas as criaturas, já que Catherine decide ser missionária na África. Esse encontro de um rosto e de um pano, que a ficção materializa por meio do quadro, Manoel de Oliveira realiza por intermediação da cortina, que consolida a proximidade do corpo, que ele não nos deixa entrever.

A carta é uma adaptação, uma montagem de fragmentos que o diretor transpôs para Paris atual, com um deslocamento do cenário e das personagens. A não aceitação do amor, por parte da Princesa de Clèves, tão bem argumentada, no livro de Madame de La Fayette é, no filme de Manoel de Oliveira, não explicitada, já que os dois enamorados jamais trocam uma palavra. As trocas de olhares e os silêncios, porém, podem ser mais eloquentes, e o amor, por parte do cantor, pode ser tão cego (os óculos podem ser um símbolo disso) como o de Nemours, no romance, o qual renunciou à expectativa de uma coroa, para permanecer perto de sua amada, mesmo não tendo conseguido com esse gesto nenhum relacionamento com a Princesa.

As personagens do romance, totalmente alheias aos problemas do mundo, comportam-se da mesma maneira no filme. Um contato com esse mundo atual, talvez, seja o momento em que as personagens assistem a um noticiário de televisão, quando Catherine solta um gemido, ao saber que Abrunhosa sofre um acidente. As três mulheres se encontram sentadas (Catherine, sua mãe, e a amiga Senhora da Silva), enquanto o marido se mantém de pé, por trás delas, formando um quadro familiar.

Entretanto, a questão que parece ser a mais importante levantada por Manoel de Oliveira, no seu filme, é a referência ao jansenismo. Guise se encontrava no Boulevard de Port 
Royal, quando foi atropelado, o que evoca, através da simples menção toponímica, tudo que se refere a Port Royal no passado. Mas é bom lembrar, que essa evocação se refere a PortRoyal-de-Champs, situada a sudoeste de Paris, e não a Port Royal de Paris (onde funcionam atualmente a Escola de Medicina e o Hospital Cochin). Port-Royal-de-Champs era, na Idade Média, um mosteiro feminino da ordem de Cister, que foi restaurado no século XVII, quando transformou-se num reduto do jansenismo. O retrato de uma religiosa jansenista, na parede do convento, e o mosteiro em si mesmo, são cenários que remetem também à famosa escola de Port Royal, e consequentemente à época de Madame de La Fayette e ao seu universo. Todavia, no seu romance, não há qualquer referência explícita ao jansenismo, mas, o rigor moral extremo das personagens é predominante em toda a obra, e isso talvez remeta ao clima da época e à ideologia da autora.

Por quê Manoel de Oliveira teria levantado a questão do jansenismo no seu filme, através de simples alusões? Antes de tudo, parece necessário precisar melhor esse conceito. $\mathrm{O}$ jansenismo é uma corrente religiosa e doutrinária, assim nomeada por causa de seu iniciador, Jansenius, bispo de Ypres (Bélgica), morto em 1638, que conquistou vastas regiões da França, Bélgica, Holanda, Itália, Alemanha, e teve muitos partidários célebres, nos séculos XVII e XVIII. Pode-se definilo, em linhas gerais, pelos seguintes princípios: rigor moral extremo, doutrina errônea sobre a graça, atribuindo valor exclusivo à Sagrada Escritura, aos Pais da Igreja, e à mística do coração. A doutrina do jansenismo sobre a graça foi fortemente condenada em 1653 (renovada, em 1715, na bula papal Unigenitus).

Um rigor moral perpassa, como foi dito, todo o livro de Madame de La Fayette, sendo também, o leitmotiv do filme de Manoel de Oliveira. Ao escolher Chiara Mastroianni, impecável no papel de uma jovem controlada, comedida em suas ações, 
em quem talvez se possa ler uma personificação da graça, no sentido filosófico e / ou religioso do termo, Manoel de Oliveira evocaria, sob forma de alegoria, a graça divina, conceito caro aos jansenistas. Seria interessante lembrar, talvez, alguns personagens célebres do jansenismo, que justificariam, no filme de Manoel de Oliveira, a evocação de Port Royal, implícita ou metonimicamente, demonstrando, dessa forma, mais um aspecto da profunda erudição do autor, e a razão de suas obras alcançarem, principalmente, os "iniciados". Antoine Arnauld, o Grande (1612-1694), teólogo e filósofo, era chefe do partido jansenista, e por causa desse título foi excluído da Sorbonne, em 1656. Arnauld era irmão da abadessa Madre Angélica, reformadora de Port Royal, e figura maior do jansenismo. Embora, os senhores de Port-Royal submetessem tudo à Graça, nos outros campos, no ramo das ciências humanas eram racionais. Arnauld desenvolveu um ramo do cartesianismo, ao qual o próprio Descartes não havia se dedicado; trata-se do estudo e da análise da linguagem, partindo da hipótese de ser ela de natureza racional. Esse ramo de estudo foi implantado e naturalizado em Port-Royal, cujo fruto é a Grammaire Générale et Raisonée de Port Royale. Acreditando na existência de mecanismos lógicos universais, que cada língua apresenta no seu próprio sistema, a gramática de Port Royal marca profundamente o nascimento da linguística moderna. Outro nome de destaque em Port Royal é o do grande filósofo Blaise Pascal (1623-1662), apologista da fé cristã, que tomou partido dos jansenistas, contra os jesuítas.

A abadia de Port-Royal era um convento de mulheres, e no século XVII, um espaço preferido pelos jansenistas, lugar de reunião, onde grandes escritores e filósofos, como os já citados Pascal e Arnauld, praticavam seus estudos de lógica, gramática, teologia e tradução dos textos da religião cristã, principalmente, a partir do grego e do hebraico. Aos grandes nomes dessa 
abadia pode-se acrescentar ainda o de Pierre Nicole, Pierre Thomas du Fossé, o mestre Louis-Isaac Lemaître de Sacy, que participaram da tradução da Bíblia, tradução dita de PortRoyal: "a mais bela realizada na França". Essa edição foi aí elaborada, entre 1657 e 1696 e seu estilo influenciou a criação literária de grandes escritores franceses como Voltaire, Victor Hugo, Flaubert, Rimbaud.

Num encontro entre literatura e cinema, o filme costuma sair, em geral, quase sempre, aquém da obra literária. Felizmente, esse não é o caso do filme de Manoel de Oliveira, aqui tratado. Ao transpor para Paris atual uma trama transcorrida no século XVI, criada no século XVII, época em que a carta tinha uma função bem marcada nas relações sociais, é claro que, a partir do final do século XX, quando outros meios de comunicação substituem aquela função da comunicação entre os indivíduos, outra solução teria que ser pensada para o filme. E o diretor português o faz com a maestria de sempre: $A$ carta, que no seu filme não é a peça-chave da narrativa, acaba por se transformar em um instrumento importante, talvez o mais importante, para denunciar o seu desencanto com o mundo atual. É talvez, a maneira que o diretor melhor achou para enviar a "sua" carta, lançada ao mundo globalizado, através daquele que é o mais importante meio de comunicação artística do século XX: o cinema. Catharine de Clèves, que se tornara uma religiosa, e servia em uma missão na Africa, enviou uma carta à sua amiga de convento. Na cena final, enquanto a religiosa a lê, aparece um retrato na parede, em close, daquela que é a figura chefe de Port Royal: Madre Angèlique Arnauld. Confirma-se assim, o diálogo com o jansenismo, e indiretamente com Madame de La Fayette, fechando o filme. 


\section{Bibliografia}

AMOSSY, R. "La lettre d'amour du réel au fictionne", La lettre entre le réel et fiction (sous la direction de Jürgen Siess) SEDES, 1998, p. 73.

CAMUS, Albert. Carnets. Paris: Gallimard, 1964.

DUCHÊNE, R. "La lettre: genre masculin et pratique féminine", L'épistolaire, un genre féminin? Études réunies et présentées par Christine Planté. Paris: Champion, 1998.

LA FAYETTE, Madame de. A princesa de Clèves. Tradução e introdução de Léo Schlafman. São Paulo: Record, 2004.

OLIVEIRA, Manoel de. A Carta. Espanha, França, Portugal. Distribuidora: Gémini Films, 1999, 1 h. 47 m.

VOLTAIRE. Le siècle de Louis XIV . Ed. par J. Hellegouarch et S. Menant. Paris: LGF, [s. d.].

\section{Resumo}

Este artigo tem como objetivo estabelecer uma comparação entre o romance do século XVII, A Princesa de Clèves e o filme $A$ Carta, do diretor português Manoel de Oliveira, cujo argumento tem como ponto de partida o romance de Madame de La Fayette. Enquanto o primeiro aborda uma temática cortês, de época, tendo o discurso epistolar como motivo principal, o segundo transpõe a trama para Paris atual, guardando, porém, aquilo que é essencial na obra da escritora francesa: a idéia do jansenismo. Em ambas as obras essa questão está apenas implícita, mas, as personagens principais e as tramas em si mesmas incorporam a ideologia jansenista. 


\section{Résumé}

Cet article a pour but une étude comparative entre le roman de Madame de La Fayette, La Princesse de Clèves et le filme La Lettre, du réalisateur portugais Manoel de Oliveira, transposé dans le Paris contemporain, d'après le roman de Madame de La Fayette. Si le premier aborde un thème courtois du XVIIe siècle avec comme motif principal le discours épistolaire, le deuxième aborde ce qui est au coeur de l'ouvrage de l'écrivaine française: l'idée du jansénisme. Dans les deux oeuvres cette question est seulement implicite, mais les personnages principaux et les trames en elles-mêmes incorporent l'idéologie janséniste. 